This is the peer reviewed version of the following article: Warwick Melannie et al. 2010, 'Self management and symptom monitoring among older adults with chronic obstructive pulmonary disease', Blackwell Publishing Ltd, vol. 66, no. 4, pp. 784-793.. which has been published in final form at http://dx.doi.org/10.1111/j.1365-2648.2009.05238.x This article may be used for non-commercial purposes in accordance With Wiley Terms and Conditions for selfarchiving' 


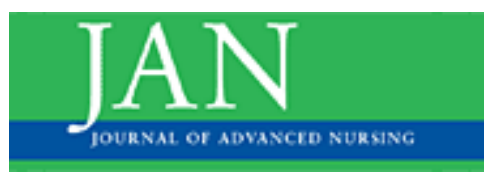

\section{Self-Management and Symptom Monitoring among Older Adults with Chronic Obstructive Pulmonary Disease}

\begin{tabular}{|r|l|}
\hline Journal: & Journal of Advanced Nursing \\
\hline Manuscript ID: & draft \\
\hline Manuscript Type: & Manuscript/Short Report \\
\hline Keywords: & $\begin{array}{l}\text { Chronic Illness, Respiratory Nursing, Psychosocial Nursing, Patient } \\
\text { participation }\end{array}$ \\
\hline
\end{tabular}

\section{今 ScholarONE




\section{Acknowledgements}

We would like to acknowledge the support of Dr Kathleen Kilstoff to Melannie Warwick and Professor Judith Donoghue for her assistance with the original conceptualization of the study.

\section{Funding}

New South Wales Nurses and Midwives Board (Category 5 Grant)

University of Technology Sydney, University Research Strength Grant 2006

\section{Conflict of Interest}

No conflict of interest has been declared by the authors. 


\section{Abstract \\ Background:}

Aims: To describe self-management, symptom monitoring, and the associated influences among older adults with chronic obstructive pulmonary disease [COPD].

Method: A prospective, descriptive survey design was used and data collected from patients with moderate COPD during home interviews between April 2005 and June 2006. Predictors of self-management and symptom monitoring were determined by linear regression analyses.

Results: Patients' ( $\mathrm{n}=78$ ) mean age was 73.37 years (SD 7.52); 55.1\% were male and $66.7 \%$ were married. Most (92.3\%) had concurrent illnesses, and $48.7 \%$ had been admitted to hospital for COPD in the past six months. Selfmanagement was good to very good, with poorer self-management predicted by lower self-efficacy, a weaker sense of coherence, and no hospitalisation in the past six months. Symptom monitoring was of a moderate level overall, with more frequent symptom monitoring occurring among participants who were married and had more severe COPD.

\section{Conclusion:}

As self-management and symptom monitoring ensure better outcomes in COPD patients, health professionals should encourage these behaviours.

Showing patients and their partners how to build self-efficacy and understand sense of coherence are fundamental to this process.

Key Words: Chronic obstructive pulmonary disease, self-management, selfefficacy, sense of coherence, symptom monitoring, older, chronic illness 


\section{Summary Statement}

\section{What is already known about this topic?}

1. Optimal self-management by COPD patients reduces dyspnoea and hospitalisations.

2. Symptom monitoring is an essential component of self-management, which promotes the early detection and initiation of treatment for acute exacerbations.

3. Self-efficacy has a positive influence on self-management in COPD.

4. Sense of coherence has a positive influence on chronic illness selfmanagement.

\section{What this paper adds}

1. Patients with moderate COPD who are supported by coordinated care programs and pulmonary rehabilitation have good to very good selfmanagement.

2. The internal resource of self-efficacy and sense of coherence have independent, positive influences on self-management in COPD.

3. Worsening illness, indicated by more severe illness and a recent hospital admission, promote self-management activities in COPD.

4. Symptom monitoring in COPD patients is less than ideal and sometimes completely absent.

5. Being married is associated with more frequent symptom monitoring by COPD patients.

\section{Implications for practice}

1. Health professionals have an important role to play in encouraging and supporting self-management in people with COPD.

2. Illness exacerbations provide a window of opportunity to motivate good self-management in COPD.

3. Interventions that promote good self-management COPD should include the development of self-efficacy and symptom monitoring.

4. COPD patients' partners should be involved in self-management interventions as they are likely to influence actual behaviours. 


\section{INTRODUCTION}

COPD, a condition characterised by progressive difficulty with breathing, is one of the most common chronic diseases globally, and is a leading cause of morbidity and mortality, particularly among older people (World Health Organisation [WHO], 2007). COPD not only affects the health status of those diagnosed, it also has a substantial impact on the utilisation of health care resources. Concurrent increases in disease prevalence and life expectancy mean that further increases in the disease burden and health care expenditure associated with COPD are likely in developed countries over the coming decades (Australian Institute of Health and Welfare [AIHW], 2004; National Heart Lung and Blood Institute [NHLBI], 2008; WHO, 2007). Therefore, the development of strategies designed to reduce health care resource burdens and to promote optimal health among individuals with COPD are increasingly important. One strategy is to ensure that individuals are actively engaged in the self-management of their illness.

\section{BACKGROUND}

\section{Self-Management}

Current estimates indicate that 70 to 80 percent of older individuals living with a chronic condition have the ability to reduce the associated disease burden through the implementation of appropriate self-management (Department of Health United Kingdom, 2007). For instance, older adults who have participated in a self-management education program experience significantly less dyspnoea and reduce the chance of a COPD-related hospital admission by $36 \%$ (Effing et al., 2007). While self-management programs have demonstrated benefits, there is a lack of assessment of participants' level of self-management, or identification of the most effective form or components of self-management education programs (Bourbeau et al., 2003; Gallefoss, Sigvald-Bakke \& Kjaersgaard, 1999; Niesink et al., 2007).

The key feature of chronic illness self-management is that the individual understands their illness and is involved in the management of their care on an ongoing basis. Optimal self-management depends critically on the attainment of several generic and disease-specific skills. Core skills include, but are not 
limited to, decision making, forming a viable patient/health care provider partnership, problem solving, managing the impact of the illness on various aspects of their lives and taking action (Lorig \& Holman, 2003). Specific skills include, but are not limited to, understanding of and ability to monitor COPD-related symptoms and respond to symptom changes.

Symptom monitoring is particularly vital among individuals with COPD, to detect the onset of repeated and increasingly severe, acute exacerbations associated with the illness (Global Initiative for Chronic Obstructive Lung Disease [GOLD], 2007). Detection and recognition of worsening symptoms such as dyspnoea, increased and more purulent sputum, cough and fatigue, also form the initial stage of implementing an action plan to treat the exacerbation (American Lung Association [ALA], 2007; GOLD, 2007; Turnock, Walters, Walters \& Wood-Baker, 2007). Individuals with COPD frequently report symptom monitoring and management as the key elements of effective everyday management of their illness (Chen, Chen, Lee, Cho \& Weng, 2008). Importantly, regular monitoring has been demonstrated to significantly improve the tracking of triggers for, and detection of, acute exacerbations, allowing and potentially motivating early initiation of treatment (Turnock et al., 2007). Identification of the factors that motivate and support symptom monitoring is, therefore, crucial knowledge for health professionals.

Aspects of self-management, such as symptom monitoring, are dependent upon multiple resources and consequently require considerable, sustained effort from individuals with COPD (Corbin, 2001; Hesselink et al., 2004). Some of these resources are external, such as having a partner or a spouse (Ashmore, Emery, Hauck \& MacIntyre, 2005), and some are internal, including positive attitudes and confidence in their capacity to manage.

\section{Self-Efficacy}

The development and performance of generic and disease-specific skills essential to self-management may be explained and predicted by several theories, the most notable being Social Cognitive Theory. This theory explains the development and maintenance of behaviours over time, and in response to 
situational demands (Lorig \& Holman, 2003). One construct within the theory, self efficacy, is particularly relevant to the development and maintenance of chronic illness self-management, as it reflects the individual's self-confidence or belief that they possess the skills required to perform the complex skills that are necessary (Bandura, 1986). Bandura (1995) indicates that among individuals who believe that they are able to competently perform a task, there is an increased probability that they will attempt the task and overcome fears of failure, whereas, individuals who do not possess this self-belief will be inclined to avoid the task. When faced with ongoing and often increasing illness demands, individuals with COPD will, therefore, persist with the recommended self-management activities, and the inclusion of these activities into their lives.

There is substantial evidence in the literature that self-efficacy is an important component of ongoing successful self-management of chronic illness (Clark \& Dodge, 1999; Conn, 1998; Foster, Taylor, Eldridge, Ramsay \& Griffiths, 2007; Lorig, Sobel, Ritter, Laurent \& Hobbs, 2001; Rapley \& Fruin, 1999; Scherer \& Bruce, 2001; Scherer \& Schmieder, 1997). Self-efficacy consistently predicts individual health-related behaviours, such as symptom monitoring and medication taking in COPD, in the short-term and long-term (Arnold et al., 2005; Chen, Wu, Yen \& Chen, 2007; Lorig, Sobel, et al., 2001; Scherer \& Bruce, 2001; Scherer \& Schmieder, 1996). The connection between self-efficacy, other personal resources, and self-management, including specifically symptom monitoring has, however, not yet been investigated in COPD.

\section{Sense of Coherence}

More pervasive personal resources, including the individual's attitude to life, may influence motivation to remain healthy and manage chronic illness as ageing occurs. The influence of the individual's overall attitude to life is explained by Antonovsky's (1987) theory, which describes how individuals remain psychologically healthy despite repeated exposure to stressful events. In essence, people aim to move themselves towards the wellness end of the health continuum by effectively coping with the various stressors and tensions 
in their lives. A core component of this resilience is the sense of coherence construct, a pervasive, enduring feeling of confidence that life and its demands are comprehensible, meaningful, and manageable (Antonovsky, 1993). Sense of coherence is an intrinsic resource in chronic illness, so that the individual with a strong sense of coherence is more likely to judge a situation as controllable and therefore worthy of the engagement required to self-manage effectively.

The association between sense of coherence and health is well supported in the literature (Eriksson \& Lindstrom, 2006) and sense of coherence has been found to be predictive of self-management among individuals with chronic illness both concurrently and over time (Gallagher, Donoghue, Chenoweth \& Stein-Parbury, 2008). In this study, Gallagher et al. (2008) found that among a heterogeneous group of individuals with a variety of chronic illness diagnoses (COPD, Chronic Heart Failure, Parkinson's disease, and Chronic Schizophrenia) individuals with COPD reported significantly better selfmanagement. Consequently, this paper specifically investigates the effects of self-efficacy and sense of coherence in the COPD sub-group, particularly focusing on symptom monitoring as a vital component of self-management. The results of the study will help determine the components most likely to contribute to effective COPD self-management interventions.

\section{THE STUDY}

\section{$\operatorname{Aim}(s)$}

The aims of this study were to: 1) describe self-management and symptom monitoring among community-dwelling older adults with COPD of moderate severity and 2) identify the influence of self-efficacy and sense of coherence, amongst other predictors, on self-management and symptom monitoring.

\section{Design}

The study employed a prospective, descriptive design and was conducted in the South Eastern Sydney and Illawarra Area Health Service in Australia between April 2005 and June 2006. Data were collected during a home interview one week following the resolution of an acute exacerbation of 
COPD. As this study forms part of a larger study on keeping well in chronic illness (Gallagher et al., 2008), elements of the method have been described previously, however, a summary is provided now.

\section{Participants}

A convenience sample of patients with COPD was recruited through biweekly screening of hospital admission records, consultations with staff of the Respiratory Coordinated Care Program [RCCP], and through hospital and community based disease-specific support programs. Patients were considered eligible if they were: 1) diagnosed with COPD of moderate severity, as classified by a total score of 10 to 34 on a modified version of the St George's Respiratory Questionnaire (Jones, Quirk \& Baveystock, 1991), 2) aged over 55 years, 3) residing in the community, 4) had a recent exacerbation of their illness, 5) participating in self-management, and 6) able to understand, supply consent, and respond to surveys in spoken or written English. Patients were excluded from the study if they had: 1) been admitted to hospital with COPD on more than one occasion in the three months prior to the commencement of the study or 2) had a major psychiatric illness.

The sample size was calculated to allow sufficient power for the multiple regression analysis using the variables: age, gender, illness severity, marital status, level of respiratory service provision, hospitalisation within the past six months, self-rated health, sense of coherence, and self-efficacy. A sample size ten times the number of independent variables is recommended for multiple regression analysis (Katz, 1999; Peduzzi, Concato, Kemper, Holford \& Feinstein, 1996). In total, the analysis included nine dichotomous and continuous variables, meaning that a sample size of 90 participants was required. To ensure this number of participants completed the study an attrition rate of 15 percent was assumed, so the sample size was determined to be 104 participants. However, recruitment was slower than anticipated, with 100 eligible participants being approached and 11 declining entry to the study. Consequently, 89 were recruited, and 78 completed the interview process, resulting in a moderate shortfall in the planned sample size. 


\section{Data Collection}

Following recruitment and informed consent, clinical and demographic data were collected from participants' medical records. Participants were then interviewed at home using a self-reported survey package, which included the Partners in Health [PIH] Scale, Self-Efficacy for Managing Chronic Disease [SEMCD] Scale, Symptom Monitoring Checklist, and the Attitude to Life Questionnaire. Interviews were usually of 45 minutes duration, and were conducted by clinical nurse specialists trained in conducting research interviews. Prior to the commencement of the main study the survey package was pilot tested on a sample of 10 participants, with no alterations to the instruments or the data collection process required, however, additional explanations of the instruments, to the participants, were incorporated.

\section{Instruments}

\section{Partners in Health Scale}

Participants' self-management of their chronic illness was assessed using the original PIH scale (Battersby, Ask, Reece, Marwick \& Collins, 2003). This self-reported survey measures generic self-management for chronic illness using 11 items, which include understanding of and ability to monitor symptoms and respond to symptom changes, disease-related knowledge, sharing in decisions, taking medications, and scheduling and attending appointments. Participants rate their ability on each item using a nine-point Likert-type scale ranging from zero (very good) to eight (very poor). Scores are then combined for a total ranging from zero to 88 , with higher scores representing poorer self-management. In this study the scale had internal consistency reliability (Cronbach's Alpha Coefficient of 0.84). The original PIH scale (a modified 13-item version is currently utilised) has been used with permission of the developers.

\section{Symptom Monitoring Checklist}

The symptom monitoring checklist was developed for the current study to determine how frequently participants monitored the five key symptoms associated with COPD identified in the St George's Respiratory Questionnaire (Jones et al., 1991). These symptoms were: dyspnoea at rest and during 
normal activities of daily living, level of fatigue, presence of cough and sputum, and sleep interruption due to dyspnoea. Participants were asked how many days each week they monitored each symptom. The weekly frequency for each symptom was then summed for a total ranging from zero (no monitoring of any symptom) to 35 (daily monitoring of all symptoms). The scale showed evidence of internal consistency reliability (Cronbach's Alpha Coefficient of 0.87).

\section{Self-Efficacy for Managing Chronic Disease Scale}

Participants' confidence in their ability to manage their chronic illness was assessed utilising the SEMCD scale (Lorig et al., 1996; Lorig, Ritter, et al., 2001; Lorig, Sobel, et al., 2001). The SEMCD scale is self-reported and consists of six items addressing the various components of self-efficacy for self-management including symptom control, role function, emotional distress, physical discomfort, self-care, and fatigue. Participants respond using a tenpoint Likert-type scale from one (not at all confident) to 10 (totally confident). Responses are then combined and a mean score calculated, ranging from one to 10 , with higher scores reflecting better self-efficacy. The scale had internal consistency reliability in this study (Cronbach's Alpha Coefficient of 0.91). The SEMCD scale is available to the public for use without permission.

\section{Attitude to Life Questionnaire}

Sense of coherence was assessed using the Attitude to Life Questionnaire (Antonovsky, 1993). The questionnaire assesses an individual's disposition toward viewing the world and their lives ad comprehensible, meaningful and manageable. The Attitude to Life Questionnaire is composed of 29 selfadministered questions and participants respond using a seven-point semantic differential scale with two anchoring phrases, which vary according to the question. Thirteen items are reversed to reduce response-set bias and responses are combined for a score ranging from 29 to 203, with higher scores reflecting a stronger sense of coherence. In the current study internal consistency was present (Cronbach's Alpha Coefficient of 0.90). The questionnaire is available to the public for use without permission. 


\section{Ethical Considerations}

Ethical approval for the study was obtained from the human research ethics committees of both the area health service and the affiliated university prior to commencement. The research conforms to the provisions of the Declaration of Helsinki 1995.

\section{Data Analysis}

All statistical analyses utilised the Statistical Package for the Social Sciences [SPSS] version 15 (SPSS Incorporated, 2007). Frequencies, percentages, means, standard deviations [SD], and medians were used to describe the data. As concurrent illnesses were frequent and overlapping, a count of these illnesses was utilised. As scores on the PIH scale were not normally distributed, they were transformed by square root for statistical analyses. Missing values were treated on a case-by-case basis. Predictors of selfmanagement and symptom monitoring were determined using multiple regression analyses and were reported if $p<0.05$. The backwards method of reduction was chosen to produce the most parsimonious model whilst accommodating complex and potentially interrelated variables (Katz, 2006). The variables: age, gender, illness severity, marital status, level of respiratory service provision, hospitalisation within the past six months, self-rated health, sense of coherence, and self-efficacy were entered into both analyses.

\section{RESULTS}

Participants in the study $(\mathrm{n}=78)$ had an average age of 73.37 years (SD 7.52), with marginally more men $(55.1 \%)$ than women as detailed in Table 1 . The majority of participants were married (66.7\%), retired (92.3\%), and from English-speaking backgrounds (87.2\%). Two thirds of the participants had COPD of moderate severity (65.4\%) and almost half (48.7\%) had been admitted to hospital within the past six months (Table 2). Concurrent illnesses were common, with $69.2 \%$ having at least two additional diagnoses. Despite this, participants reported their overall health as good to very good, with a mean score of 3.81 (SD 0.95). Most participants were receiving COPD-related support services, with $74.4 \%$ enrolled in pulmonary rehabilitation and $38.5 \%$ enrolled in the Respiratory Coordinate Care Program. 
The average participant had a moderate sense of coherence score (mean 140.75; SD 24.63), moderately high self-efficacy for managing their chronic illness (mean 6.51; SD 2.27), and reported good to very good levels of selfmanagement of their COPD (mean 14.83; SD 13.37) (Table 3). Of the five symptom monitoring behaviours that were assessed, the symptom of dyspnoea during normal activities of daily living was most frequently monitored, being checked every day by $60 \%$ of the participants (Figure 1). The symptom monitored least often was sleep interruption due to dyspnoea, with $50 \%$ of participants indicating that they did not monitor this symptom at all.

The results of the multiple regression analyses for self-management and symptom monitoring are reported in Table 4. The significant independent predictors of self-management were self-efficacy, sense of coherence and hospitalisation within the six months prior to the commencement of the study, with the final model accounting for 34 percent of the variance in selfmanagement. When other variables were held constant, participants with higher levels of self-efficacy, a stronger sense of coherence, and those who had been admitted to hospital in the past six months reported better selfmanagement. The significant independent predictors of symptom monitoring were illness severity and marital status, which explained 35 percent of the variance in symptom monitoring. When other variables were held constant, participants with more severe COPD and those who were married reported higher levels of symptom monitoring.

\section{DISCUSSION}

\section{Study Limitations}

This study utilised self-reported measures, therefore, the results may be affected by poor recall and/or social desirability bias. Also, most of the measures had been extensively tested, however, the symptom monitoring checklist had not been used prior to the commencement of this study. There was also a moderate shortfall in sample size, which may have limited the ability of the analyses to detect differences and associations where they were present (Katz, 1999; Peduzzi et al., 1996). Finally, since the majority of the 
participants in this study were receiving COPD-specific support services, this may limit the generalisability of the results to patients receiving fewer or no disease-specific support services.

\section{Discussion of Findings}

The patients in this study were self-managing their COPD well, and better than previous reports of patients with COPD and other chronic illnesses including Parkinson's disease, and diabetes mellitus (Battersby et al., 2003; Chenoweth, Gallagher, Sheriff, Donoghue \& Stein-Parbury, 2008; Gallagher et al., 2008). This may be because the majority of patients in this study were receiving COPD-related support services which have been shown to improve disease management (GOLD, 2007; Lacasse et al., 2006).

Despite relatively high levels of self-management, symptom monitoring was less than ideal, with more than 20 percent of participants not monitoring any of the five key symptoms at all. This is an important finding, given that almost half of the sample had been hospitalised for their COPD in the past six months. While hospital admissions for repeated and increasingly severe exacerbations are part of the illness trajectory in COPD, they are important to limit as hospitalisation is costly and illness exacerbation frequently associated with irreversible functional impairment and reductions in health-related quality of life, in the immediate and the long term (O'Reilly, Williams \& Rice, 2007). Identifying the factors that motivate and/or support symptom monitoring to avoid deteriorating health and hospitalisation is, therefore, vital.

In contrast to overall self-management, the internal resources of self-efficacy and sense of coherence were not associated with symptom monitoring, whereas, having a spouse and increasing illness severity were. Being married has powerful positive effects for individuals with chronic illnesses, resulting in decreased morbidity and mortality (Kiecolt-Glaser \& Newton, 2001). Having a spouse may have direct and indirect effects for individuals with COPD. As COPD symptoms are relatively marked (dyspnoea, cough, sputum production, and fatigue), spouses are well-positioned, not only to motivate their partner to monitor symptoms, but also to participate in this task themselves. Spouses are 
motivated to provide this support because the losses in physical and psychological functioning that occur as a result of acute exacerbations and hospitalisations directly affect quality of life, at the least in terms of marital adjustment (Ashmore et al., 2005). It is therefore likely that having a spouse offers many other benefits to patients with COPD and this is worthy of further exploration.

Increased severity of illness, acute exacerbations, and hospital admissions are common features of the COPD trajectory and typically indicate to the patient and their family, that their condition is worsening or that there are gaps in the management of their illness (Connolly \& Kent, 2005). Not surprisingly then, having more severe COPD was associated with more frequent symptom monitoring and a recent COPD-related hospital admission, which were both associated with better overall self-management. Following a COPD-related hospital admission, patients experience impaired functionality and a reduction in health status for several months, so it is likely that optimal involvement in self-management activities was necessary to manage symptoms which were eliciting an increasingly pervasive effect on participants' lives (O'Reilly et al, 2007). Similarly, among patients with more severe illness, additional attention to self-management is required, as is further motivation to avoid ongoing degradation of quality of life from acute exacerbations and hospital admissions.

In contrast to symptom monitoring, the personal resources of self-efficacy and sense of coherence proved important contributors to self-management. Despite the variable nature and severity of illness, the role of self-efficacy in supporting the development and maintenance of self-management confirms previous reports (Arnold et al., 2005; Clark \& Dodge, 1999; Conn, 1998; Foster et al., 2007; Lorig, Sobel, et al., 2001; Scherer \& Bruce, 2001; Scherer $\&$ Schmieder, 1996). Since self-efficacy levels in this sample were relatively high compared with previous studies, this was most likely due to the levels of disease-specific support offered by the RCCP and pulmonary rehabilitation programs. It is, therefore, worthwhile for health professionals to assess self- 
efficacy in COPD patients, identify strategies that build up self-efficacy and to prioritise care for those with lower self-efficacy.

The role of sense of coherence as a self-management resource has been strengthened by this study. Sense of coherence levels were moderate in our sample, similar to individuals with other chronic conditions, including Parkinson's disease (Chenoweth, Gallagher, Sheriff, Donoghue \& SteinParbury, 2008; Margalit \& Cassel-Seidenman, 1987; Petrie \& Azariah 1990). As others have suggested, sense of coherence most likely fosters persistence, so that in the face of ongoing and increasing issues related to COPD, patients find their lives comprehensible, meaningful, and manageable (Antonovsky, 1993; Eriksson \& Lindstrom, 2006). It is not clear, however, if sense of coherence is amenable to intervention or a relatively stable personality characteristic, this debate continues in the literature. Collectively, self-efficacy and sense of coherence are likely to contribute to resilience as both are healthpromoting factors which contribute to better coping when facing life's challenges, including issues related to health (Bandura, 1995; Eriksson \& Lindstrom, 2006). Therefore, if self-efficacy and sense of coherence are both strong, patients are more likely to overcome negative influences on selfmanagement, such as acute exacerbations. When they are confronted with such setbacks, they are able to overcome many through persistence with the recommended self-management activities and subsequent lifestyle adjustments (Antonovsky, 1996; Bandura, 1995).

\section{CONCLUSION}

In COPD patients self-management is an essential ingredient for better quality of life. Symptom monitoring is a vital component of this self-management. Health professionals have an ideal opportunity to encourage and support symptom monitoring so that the patient with COPD takes greater control of their disease and is able to achieve better quality of life through good selfmanagement. Showing patients and their partners how to build self-efficacy and understand sense of coherence are fundamental to this process. 


\section{REFERENCES}

American Lung Association. (2007). Chronic obstructive pulmonary disease [COPD]: Fact sheet. [Online]. Available: http://www.lungsa.org/site/apps/nlnet/depression/anxietyconte nt 3 .aspx $? \mathrm{c}=$ dvluk900E $\& \mathrm{~b}=2058819 \&$ contentid $=\{$ EE451F66996B-4C23-874D-BF66586196FF] \&notoc=1 [2008, March 26].

Antonovsky, A. (1987). Unraveling the mystery of health: How people manage stress and stay well. San Francisco: Jossey-Bass Publishers.

Antonovsky, A. (1993). The structure and properties of the sense of coherence scale. Social Science and Medicine, 36 (6), 725-733.

Antonovsky, A. (1996). The sense of coherence: An historical and future perspective. Israel Journal of Medical Science, 32, 170-178.

Arnold, R., Ranchor, A., Dojonste, M., Koeter, G., Ten-Hacken, N., Aalbers, R., \& Sanderman, R. (2005). The relationship between selfefficacy and self-reported physical functioning in chronic obstructive pulmonary disease and chronic heart failure. Behavioural Medicine, 31 (3), 107-115.

Ashmore, J., Emery, C., Hauck, E., \& MacIntyre, N. (2005). Marital adjustment among patients with chronic obstructive pulmonary disease who are participating in pulmonary rehabilitation. Heart and Lung, 34, 270-278.

Australian Institute of Health and Welfare. (2004). Australia's health 2004. Canberra: Australian Institute of health and Welfare.

Bandura, A. (1986) Social foundations of thought and action: A social cognitive theory. Englewood Cliffs: Prentice Hall.

Bandura, A. (1995). Self-efficacy in changing societies. Cambridge: Cambridge University Press.

Battersby, M., Ask, A., Reece, M., Marwick, M., \& Collins, J. (2003). The partners in health scale: Development and psychometric properties of a generic assessment scale for chronic condition self-management. Australian Journal of Primary Health, 9, 4152.

Bourbeau, J., Julien, M., Maltais, F., Rouleau, M., Beaupre, A., Begin, R., Renzi, P., Nault, D., Borycki, E., Schwartzman, K., Singh, R., \& Collet, J. (2003). Reduction of hospital utilization in patients with chronic obstructive pulmonary disease: A disease-specific 
self-management intervention. Achirves of Internal Medicine, $163,585-591$.

Chen, K., Chen, M., Lee, S., Cho, H., \& Weng, L. (2008). Self-management behaviours for patients with chronic obstructive pulmonary disease: A qualitative study. Journal of Advanced Nursing, 64 (6), 595-604.

Chen, C., Wu, J., Yen, M., \& Chen, Z. (2007). A model of medication-taking behaviour in elderly individuals with chronic disease. Journal of Cardiovascular Nursing, 22 (5), 359-365.

Chenoweth, L., Gallagher, R., Sheriff, J., Donoghue, J., Stein-Parbury, J. (2008). Factors supporting self-management in Parkinson's disease: Implications for nursing practice. International Journal of Older People Nursing, 3 (3), 187-193.

Clark, N., \& Dodge, J. (1999). Exploring self-efficacy as a predictor of disease management. Health Education and Behavior, 26 (1), 72-89.

Conn, V. (1998). Older adults and exercise: Path analysis of self-efficacy related constructs. Nursing Research, 47 (3), 180-189.

Connolly, M., and Kent, B. (2005). Nursing management: Obstructive pulmonary disease. In D. Brown., H. Edwards., S. Lewis., M. Heitkemper., \& S. Dirkson (Eds.). Lewis's medical-surgical nursing: Assessment and management of clinical problems (pp.641-689). Marrickville: Elsevier.

Corbin, J. (2001). Introduction and overview: Chronic illness and nursing. In R. Hayman., \& J. Corbin (Eds.). Chronic illness: Research and theory for nursing practice (pp. 4-5). New York: Springer Publishing Company.

Department of Health. (2007). The national health service and social care long-term conditions model. [Online]. Available: http://www.dh.gov.uk/en/Policyguidance/Healthandsense of coherenceialcaretopics/Longtermconditions/DH_4130652 [2007, October 24].

Effing, T., Monninkhof, E., Van Der Valk, P., Van Der Palen, J., Van Herwaarden, C., Partridge, M., Walters, E., \& Zielhuis. (2007). Self-management education for patients with chronic obstructive pulmonary disease [systematic review]. Cochrane Database of Systematic Reviews, 4. [Online]. Available: http://ovidsp.tx.ovid.com.ezproxy.lib.uts.edu.au/spa/ovidweb.c gi [2008, May 16]. 
Eriksson, M., \& Lindstrom, B. (2006). Antonovsky's sense of coherence scale and it's relation with health: A systematic review. Journal of Epidemiology and Community Health, 60, 376-381.

Foster, G., Taylor, S., Eldridge, S., Ramsay, J., \& Griffiths, G. (2007). Selfmanagement education programmes by lay leaders for people with chronic conditions [systematic review]. Cochrane Database of Systematic Reviews, 4. [Online]. Available: http://ovidsp.tx.ovid.com.ezproxy.lib.uts.edu.au/spb/ovidweb.c gi [2008, June 2].

Gallagher, R., Donoghue, J., Chenoweth, L., \& Stein-Parbury, J. (2008). Selfmanagement in older patients with chronic illness. International Journal of Nursing Practice, 14, 372-381.

Gallefoss, F., Sigvald-Bakke, P., \& Kjaersgaard, P. (1999). Quality of life assessment after patient education in a randomized controlled study on asthma and chronic obstructive pulmonary disease. American Journal of Respiratory and Critical Care Medicine, $159,812-817$.

Global Initiative for Chronic Obstructive Lung Disease. (2007). Global strategy for the diagnosis, management and prevention of COPD. [Online]. Available: http://www.goldcopd.org. [2008, February 19].

Hesselink, A., Penninx, B., Schlosser, M., Wijnhoven, H., Van Der Windt, D., Kriegsman, D., \& Van Eijk, J. (2004). The role of coping resources and coping style in quality of life of patients with asthma or COPD. Quality of Life Research, 13, 509-518.

Jones, P., Quirk, F., \& Baveystock, C. (1991). The St George's Respiratory Questionnaire. Respiratory Medicine, 85 (Supplement B), 2531 .

Chen KH Chen ML Lee S Cho HY Weng LC Self-management behaviours for patients with chronic obstructive pulmonary disease: a qualitative study. Journal of Advanced Nursing 2008:64: 595604.

Katz, M. (1999). Multivariable analysis: A practical guide for clinicians. Cambridge: Cambridge University Press.

Katz, M. (2006). Multivariate analysis: A practical guide for clinicians $\left(2^{\text {nd }}\right.$ ed.). Cambridge: Cambridge University Press.

Kiecolt-Glaser, J., \& Newton, T. (2001). Marriage and health: His and hers. Psychological Bulletin, 127, 472-503. 
Lorig, K., \& Holman, H. (2003). Self-management education: History, definition, outcomes, and mechanisms. Annals of Behavioral Medicine, 26 (1), 1-7.

Lorig, K., Ritter, P., Stewart, A., Sobel, D., Brown, B., Bandura, A., Gonzalez, V., Laurent, D., \& Holman, H. (2001). Chronic disease selfmanagement program: 2-Year health status and health care utilisation. Medical Care, 39, 1217-1223.

Lorig, K., Sobel, D., Ritter, P., Laurent, D., \& Hobbs, M. (2001). Effect of a self-management program on patients with chronic disease. Effective Clinical Practice, 4, 256-262.

Lorig, K., Stewart, A., Ritter, P., González, V., Laurent, D., \& Lynch, J. (1996). Outcome measures for health education and other health care interventions. Thousand Oaks CA: Sage Publications.

Margalit, M. \& Cassel-Seidenman, R. (1987). Life satisfactions and sense of coherence among young adults with cerebral palsy. Journal of Career Development and Career Development for Exceptional Individuals, 10, 42-50.

National Heart Lung and Blood Institute. (2008). What is COPD? [Online]. Available: http://www.nhlbi.nih.gov/health/dci/Diseases/Copd/Copd_Wha tIs.html [2009, February 10].

Niesink, A., Trappenburg, J., Weert-Van Oene, G., Lammers, J., Verheij, T., $\&$ Schrijvers, A. (2007). Systematic review of the effects of chronic disease management on quality-of-life in people with chronic obstructive pulmonary disease. Respiratory Medicine, 101, 2233-2239.

O’Reilly, J., Williams, A., \& Rice, L. (2007). Health status impairment and costs associated with COPD exacerbations managed in hospital. International Journal of Clinical Practice, 61 (7), 1112-1120.

Peduzzi, P., Concato, U., Kemper, E., Holford, T., \& Feinstein, A. (1996). A simulation study of the number of events per variable in multiple regression analysis. Journal of Clinical Epidemiology, 49, 360-374.

Petrie, K., \& Azariah, R. (1990). Health-promoting variables as predictors of response to a brief pain management program. Clinical Journal of Pain, 6, 43-46. 
Rapley, P., \& Fruin, D. (1999). Self-efficacy in chronic illness: The juxtaposition of general and regimen-specific efficacy. International Journal of Nursing Practice, 5, 209-215.

Scherer, Y., \& Bruce, S. (2001). Knowledge, attitudes, self-efficacy and compliance with medical regimen, number of emergency department visits, and hospitalisations in adults with asthma. Heart and Lung, 30 (4), 250-257.

Scherer, Y., \& Schmieder, L. (1996). The role of self-efficacy in assisting patients with chronic obstructive pulmonary disease to manage breathing difficulty. Clinical Nursing Research, 5 (3), 343-355.

Scherer, Y., \& Schmieder, L. (1997). The effect of a pulmonary rehabilitation program on self-efficacy, perception of dyspnea, and physical endurance. Heart and Lung, 26 (1), 15-22.

Statistical Package for the Social Sciences Incorporated. (2007). SPSS survival manual ( $3^{\text {rd }}$ ed.). Sydney: Allen \& Unwin.

Turnock, A., Walters, E., Walters, J., Wood-Baker, R. (2005). Action plans for chronic obstructive pulmonary disease [systematic review]. Cochrane Database of Systematic Reviews, 4. [Online]. Available: http://ovidsp.tx.ovid.com.ezproxy.lib.uts.edu.au/spa/ovidweb.c gi [2008, May 16].

World Health Organisation. (2007). Chronic obstructive pulmonary disease (COPD). [Online]. Available: http://www.who.int/mediacente/factsheets/fs315/en/index.html [2007, February 19]. 
Figure 1. Percentage of Participants who Undertake Symptom

\section{Monitoring}

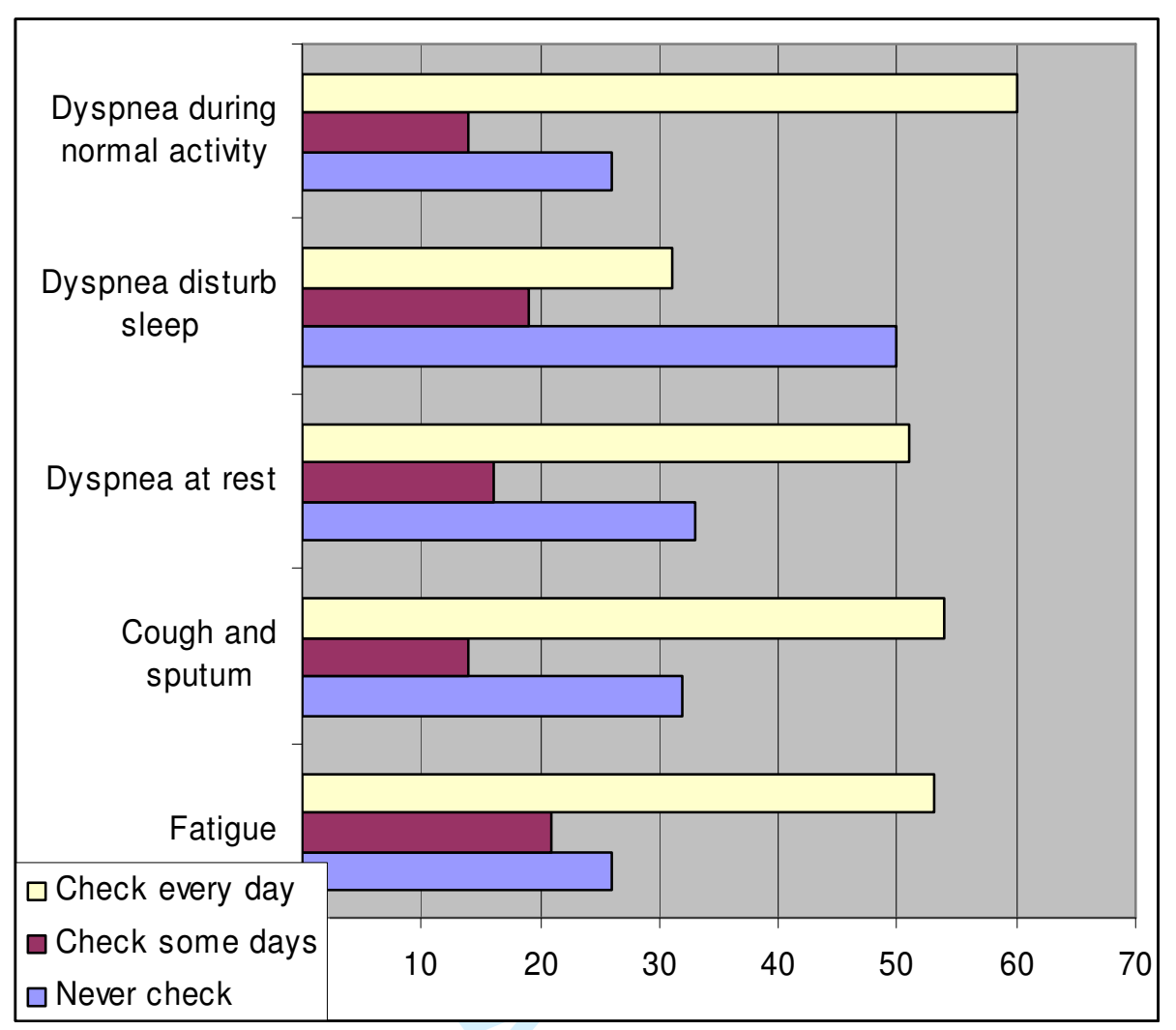


Table 1. Sociodemographic Characteristics $(n=78)$

\begin{tabular}{lr}
\hline Characteristic & Mean (SD) \\
\hline Age (years) & $73.37(7.52)$ \\
Education (years) & $10.92(2.67)$ \\
& Number (\%) \\
Gender, male & $43(55.1)$ \\
Employment status, retired & $72(92.3)$ \\
Marital status, married & $52(66.7)$ \\
Lives alone & $22(28.2)$ \\
Culturally and linguistically diverse & $10(12.8)$ \\
Smoke cigarettes & $5(6.4)$ \\
Drinks alcohol & $42(53.8)$ \\
\hline
\end{tabular}


Table 2. Clinical Characteristics

\begin{tabular}{lr}
\hline Characteristic & Mean (SD) \\
\hline Disease severity $^{\mathrm{a}}$ & $30.25(8.06)$ \\
Number of comorbidities (not including primary) & $2.28(1.38)$ \\
Self-rated health $^{\mathrm{b}}$ & $3.81(0.95)$ \\
& Number (\%) \\
Hospitalised in the past six months & $38(48.7)$ \\
Prescribed home oxygen therapy $_{\text {Enrolled in pulmonary rehabilitation }}$ & $24(30.8)$ \\
Enrolled in Respiratory Coordinated Care Program & $58(74.4)$ \\
\hline Potential range ${ }^{\mathrm{a}}\left[1\right.$ (no limitation)-51 (severe limitation)], ${ }^{\mathrm{b}}[1$ (excellent)-5 (poor)].
\end{tabular}


Table 3. Self-Management Characteristics

\begin{tabular}{|c|c|}
\hline Characteristic & Mean (SD) \\
\hline Self-efficacy ${ }^{a}$ & $6.51(2.27)$ \\
\hline Sense of Coherence ${ }^{b}$ & $140.75(24.63)$ \\
\hline Symptom monitoring $^{c}$ & $19.63(11.55)$ \\
\hline Self-management ${ }^{\mathrm{d}}$ & $14.83(13.37)$ \\
\hline
\end{tabular}


Table 4. Predictors of Self-Management ${ }^{\mathrm{a}}$ and Symptom Monitoring ${ }^{\mathrm{b}}$

\begin{tabular}{lccc}
\hline Predictors & $\boldsymbol{B}^{\mathbf{c}}$ & $\mathbf{9 5 \%} \mathbf{C I}^{\mathbf{d}}$ & $\boldsymbol{p}$-value \\
\hline Self Management $^{\mathrm{a}}$ & & & \\
Self-efficacy & -0.21 & $-0.41--0.01$ & .046 \\
Sense of Coherence (Total) & -0.03 & $-0.05--0.01$ & .002 \\
Hospitalised in the past six months & -1.05 & $-1.8--0.27$ & .009 \\
Constant & 9.36 & & \\
$\quad$ Model $F$ test $=4.41, \mathrm{df}=75, p<.001, \mathrm{R}^{2}=0.34$ & & \\
\hline
\end{tabular}

Symptom Monitoring ${ }^{b}$

Illness severity

$0.79 \quad 0.51-1.07<.001$

Married

$5.14 \quad 0.51-9.75$

Constant

Model $F$ test $=15, \mathrm{df}=68, p<.001, \mathrm{R}^{2}=0.35$

Potential range ${ }^{\mathrm{a}}[0$ (very good) -88 (very poor) $],{ }^{\mathrm{b}}[0$ (no monitoring)- 35 (daily monitoring of symptoms)]. ${ }^{\mathrm{c}}$ Unstandardised Beta Coefficient. ${ }^{\mathrm{d}} 95 \%$ confidence interval for Unstandardised Beta Coefficient. 
$8^{\text {th }}$ April 2009

The Editor

Journal of Advanced Nursing

Dear Sir or Madam,

Please find attached a manuscript entitled: Self-Management and Symptom Monitoring among Older Adults with Chronic Obstructive Pulmonary Disease

The manuscript presents results from original research. The authors will assign copyright to the Journal of Advanced Nursing on acceptance of the manuscript. We would be happy to engage in any process of review and revision if this is required. The corresponding author's address is listed below.

Yours sincerely,

Robyn Gallagher

Associate Professor, Chronic and Complex Care

Faculty of Nursing, Midwifery and Health

University of Technology, Sydney

PO Box 123 Broadway NSW 2007

Australia

Email: Robyn.Gallagher@uts.edu.au 